\title{
Quadro seroproteico como auxilio diagnóstico na anemia hemolítica imunomediada em cães
}

\author{
Serum proteic profile as diagnosis aids in immune-mediated hemolytic anemia in dogs
}

\author{
Patrícia Mendes Pereira $^{\mathrm{I}^{*}}$ Dilayla Kelly de Abreu ${ }^{\mathrm{II}}$ Vanessa Andrea Pincelli ${ }^{\mathrm{I}}$ \\ Mariana Menezes BochioI Áureo Evangelista Santana ${ }^{I I I}$
}

\section{RESUMO}

No presente protocolo experimental, determinaram-se os proteinogramas séricos, por intermédio da eletroforese em gel de poliacrilamida contendo duodecil sulfato de sódio (SDS-PAGE), de 120 cães com raças e idades variadas e atendidos junto ao Hospital Veterinário "Governador Laudo Natel" da FCAV/Unesp, com o objetivo principal de comparar diferentes frações seroproteicas em estados anêmicos regenerativos, arregenerativos, imunomediados primários $e$ secundários. Os referidos animais foram distribuídos em cinco grupos experimentais: grupo 1: 20 cães de controle; grupo 2: 28 cães com anemia regenerativa não imune; grupo 3: 27 cães com anemia arregenerativa não imune; grupo 4: 10 cães com anemia hemolítica imunomediada primária; grupo 5: 35 cães com anemia hemolítica imunomediada secundária. A técnica SDS-PAGE permitiu o fracionamento de 24 proteínas, cujos pesos moleculares (PM) variaram de 18.000 a 165.000 daltons (Da). Os cães com AHIM primária e secundária apresentaram 24 frações proteicas em seus traçados eletroforéticos, enquanto que cães de controle (1) e portadores de anemia regenerativa (2) e arregenerativa (3) de natureza não imune apresentaram 23 frações de proteínas, cuja proteína de peso molecular 68.000Da não foi encontrada. Dessa forma, 23 frações proteicas foram detectadas e revelaram-se comuns aos proteinogramas dos cães de controle e daqueles dos quatro grupos experimentais. Destas, identificaram-se nominalmente 11 frações proteicas, e as demais foram estudadas com base nos seus respectivos pesos moleculares. Em relação aos cães de controle, os anêmicos (grupos 2, 3, 4 e 5) apresentaram maiores concentrações de transferrina sérica e entre estes os animais portadores da AHIM primária. Todos os cães anêmicos apresentaram teores séricos de haptoglobina e fosforilase significativamente maiores que os controles, enquanto que a concentração sérica de ceruloplasmina foi significativamente maior nestes. Tais achados analisados em conjunto agregam informações adicionais úteis à elucidação das AHIMs em cães.
Palavras-chave: anemia hemolítica imunomediada, cães, eletroforese em gel de poliacrilamida, proteínas plasmáticas.

\section{ABSTRACT}

This assay aimed to determine the serum protein - via polyacrylamide gel electrophoresis, which contained duodecil sodium sulfate (SDS-PAGE) - in 120 dogs, with different breeds and ages, seen by the Veterinary Hospital "Governor Laudo Natel." These animals were grouped into five experimental groups: Group 1 - group control with 20 dogs, group 2 - 28 dogs with regenerative anemia; group 3 27 dogs with arregenarative; anemia group 4 - 10 dogs with primary immune-mediated hemolytic anemia (AHIM 1.rd); group 5 - 35 dogs with secondary immune-mediated hemolytic anemia (AHIM 2.rd). The technique allowed the SDS-PAGE fractionation of 24 protein, whose molecular weights (PM) ranged from 18,000 to 165,000 daltons (Da). The dogs with $1^{\text {st }}$ and $2^{\text {nd }}$ AHIM showed 24 protein fractions in their tracks electrophoretic, while other groups of dogs showed 23 fractions of protein, whose molecular protein weight of 68,000Da was not found. Thus, twenty-three proteins were common to proteinograms of the five experimental groups. From these, it was possible to identify eleven protein fractions nominally, and others were identified by their molecular weights. For control dogs, the anemic (groups 2, 3, 4 and 5) showed higher concentrations of serum transferrin and between them, the animals carrying the primary IMHA. All groups of dogs showed anemic levels of serum haptoglobin and phosphorylase

IDepartamento de Clínica Veterinária, Centro de Ciências Agrárias (CCA), Universidade Estadual de Londrina (UEL), Campus Universitário, CP 6001, 86051-990, Londrina, PR, Brasil. E-mail: pmendes@uel.br. *Autor para correspondência.

IIDepartamento de Cirurgia, Setor de Anatomia, Faculdade de Medicina Veterinária e Zootecnia (FMVZ), Universidade de São Paulo (USP), São Paulo, SP, Brasil.

IIIDepartamento de Clínica e Cirurgia Veterinária, Faculdade de Ciências Agrárias e Veterinárias (FCAV), Universidade Estadual Paulista (UNESP), Jaboticabal, SP, Brasil. 
significantly higher than the control dogs, while the serum ceruloplasmin was lower in anemic dogs. These findings provide additional information to the elucidation of the AHIMs in dogs.

Key words: immune-mediated hemolytic anemia, dogs, of polyacrylamide gel electrophoresis, plasma proteins.

\section{INTRODUÇÃO}

Uma das enfermidades de natureza imune mais comum em cães é a anemia hemolítica imunomediada (AHIM). Apesar do grande número de cães anêmicos no Brasil, há poucas referências sobre a prevalência e os achados clínico-laboratoriais em anemias de origem imune em cães (BRANDÃO et al., 2003). Essa enfermidade resulta de uma reação de hipersensibilidade tipo II, apresentando aspectos patofisiológicos complexos que traduzem o fenômeno no qual os eritrócitos são cobertos por imunoglobulinas, complemento, ou ambos, e subsequentemente são removidos da circulação por destruição direta e/ou fagocitose (BRANDÃO et al., 2003).

Entre os achados clínico-patológicos que podem trazer informações adicionais à elucidação das AHIMs, incluem-se as alterações das concentrações das proteínas séricas (KANEKO et al., 1997). As proteínas funcionam como catalisadores enzimáticos em reações bioquímicas, carreadores de muitos constituintes do plasma e como anticorpos na defesa orgânica (JAIN, 1993; KANEKO et al., 1997).

No conjunto das proteínas totais do soro, a albumina é a fração sérica mais abundante, compreendendo aproximadamente de 35 a 50\% das proteínas séricas totais (KANEKO et al., 1997). A transferrina é a betaglobulina sérica que transporta o ferro. Sua capacidade de ligação com o ferro pode ser avaliada por meio de sua concentração sérica (JAIN, 1993). Os anticorpos são glicoproteínas denominadas imunoglobulinas (Ig), as quais, além de exercerem função protetora mediando a resposta imunitária do hospedeiro, também se revelam como importantes componentes envolvidos na patogênese e progressão de muitas desordens imunomediadas (STEINMAN, 1995). Dentre as glicoproteínas, podem ser citadas a ceruloplasmina, a haptoglobina e a glicoproteína ácida alfa-1 ou seromucoide. Muitas dessas frações proteicas são reconhecidas como proteínas de fase aguda, visto que suas concentrações plasmáticas aumentam rapidamente no início de processos inflamatórios em muitas espécies domésticas (MURATA et al., 2004; CERÓN et al., 2005).
Também há relatos bem consistentes sobre variações nos níveis de várias frações proteicas associadas a diversas condições patológicas em cães e gatos (VAN DEN BROEK, 1992; ECKERSALL, 2000; ANDERSSON \& SEVELIUS, 2001). Contudo, poucas são as referências que dizem respeito ao perfil seroproteico de cães com AHIMs, especialmente com ênfase no seu diagnóstico e prognóstico. A determinação das concentrações séricas de proteínas constitui-se em um procedimento valioso para o entendimento dos processos fisiopatológicos, sendo aplicada, tanto em cães hígidos, quanto doentes (GODOY et al., 2006; STROTTMANN et al., 2008). Pesquisas recentes têm evidenciado que a quantificação e a qualificação de proteínas séricas podem subsidiar o diagnóstico e trazer valiosas informações prognósticas e de monitoramento de diversas doenças (ECKERSALL, 2000).

O fracionamento eletroforético representa um dos mais confiáveis métodos de quantificação de proteínas sanguíneas (KANEKO et al., 1997; FELDMAN et al., 2000). A técnica de eletroforese em gel de poliacrilamida contendo duodecil sulfato de sódio (SDS-PAGE) é relativamente simples, de baixo custo e permite a detecção de concentrações proteicas extremamente baixas, além da identificação de 20 a 30 tipos diferentes de proteínas, necessitando de diminutas quantidades de amostra (GORDON, 1995).

Com base nesse contexto, os objetivos deste trabalho foram avaliar e comparar os níveis séricos das proteínas de cães portadores de AHIMs primária e secundária, com anemia regenerativa e arregenerativa não imunomediadas, atendidos junto ao Hospital Veterinário “Governador Laudo Natel” da Faculdade de Ciências Agrárias e Veterinárias - UNESP - Campus de Jaboticabal, São Paulo.

\section{MATERIAL E MÉTODOS}

Os animais foram distribuídos em cinco grupos, como segue: Grupo 1: controle $(n=20)$; Grupo 2: anemia regenerativa não imune $(\mathrm{n}=28)$; Grupo 3: anemia arregenerativa não imune $(n=27)$; Grupo 4: AHIM de causa primária ( $n=10)$ e Grupo 5: AHIM de causa secundária $(n=35)$. O critério para inclusão dos animais no protocolo de estudo foi a presença de anemia moderada a severa (volume globular abaixo de $26 \%$ e taxa de hemoglobina inferior a $10 \mathrm{~g} \mathrm{dL}^{-1}$ ), regenerativa ou não. Para inclusão de cães com AHIM, foram considerados os critérios de positividade para o teste de Coomb’s e/ou presenças de autoaglutinação 
e/ou esferócitos, mesmo em baixa concentração, considerando que os outros testes serão complementares para a conclusão diagnóstica. Cães com anemia regenerativa decorrente de sangramento ativo (trauma) ou que estivessem sob tratamento com doxiciclina, imidocarb ou terapias imunossupressoras não foram incluídos no referido protocolo. Para diferenciar a AHIM primária da secundária, foi considerado o histórico prévio de erlichiose, babesiose, medicamentos, vacinas, entre outros fatores, e a clínica do paciente. Com a presença desses fatores, é possível classificar como AHIM de causa secundária. Para o grupo de controle, foram considerados animais hígidos, avaliados clínica e laboratorialmente (volume globular acima de $26 \%$ e taxa de hemoglobina superior a $10 \mathrm{~g} \mathrm{dL}^{-1}$ ).

Para obtenção do eletroforetograma, as amostras de soro foram aplicadas em gel de poliacrilamida contendo duodecil sulfato de sódio (SDS-PAGE), segundo técnica descrita por LAEMMLI (1970). Uma vez concluída a corrida eletroforética, os pesos moleculares e as concentrações das frações proteicas foram determinados por densitometria (densitômetro Shimadzu CS-9301). A identificação das proteínas foi feita com auxílio de marcadores com pesos moleculares de 29.000Da, 45.000Da, 66.000Da, 94.000Da e 205.000Da e proteínas purificadas (haptoglobina, ceruloplasmina, transferrina, $\alpha_{1}$-antitripsina e imunoglobulina $G$ ), já a quantificação das respectivas bandas foi realizada com base na confecção de curvas de referência.

A análise estatística dos dados obedeceu a um esquema de variância de medidas repetidas, cujos resultados foram submetidos, nos casos de diferença significativa, ao Teste de Tukey de comparação de médias, com 5\% de probabilidade.

\section{RESULTADOS E DISCUSSÃO}

Os valores médios, desvios-padrão e valores mínimos e máximos dos teores séricos das frações proteicas, obtidas por fracionamento em gel de poliacrilamida contendo duodecil sulfato de sódio, dos grupos de animais estudados estão apresentados nas tabelas 1, 2, 3 e 4. De acordo com essas tabelas, a técnica SDS-PAGE permitiu o fracionamento de 24 proteínas no traçado eletroforético, cujos pesos moleculares (PM) variaram de 18.000 a 165.000Da. Os animais de controle e aqueles portadores de anemia não imunomediada exibiram eletroforetograma com 23 frações de proteínas séricas. Já os cães com AHIMs primária e secundária apresentaram 24 frações proteicas no traçado eletroforético. Verificou-se uma fração de peso molecular de 68.000Da, não presente nos eletroforetrogramas de cães de controle, nem naqueles com anemia não imunomediada.

Por outro lado, a comparação das supracitadas frações proteicas com os pesos moleculares das proteínas de referência permitiu a identificação nominal de 11 delas, e as demais foram classificadas de acordo com os respectivos pesos moleculares. Nesse aspecto, conforme afirmaram FAGLIARI \& SILVA (2002), a atual indisponibilidade de outras proteínas específicas purificadas limita a identificação nominal de todas as frações presentes no traçado eletroforético, mas não inviabiliza a utilização da eletroforese em SDS-PAGE como método auxiliar de diagnóstico e outros estudos.

Os dados obtidos mostram que as concentrações séricas de fosforilase (Tabela 2) apresentaram-se significativamente menores nos cães controles. Já em relação à albumina (Tabela 3), sua a concentração sérica foi significativamente maior nos cães de controle. Além disso, os teores séricos de transferrina (Tabela 2) foram significativamente menores para os cães de controle e maiores para aqueles portadores de AHIM primária, que apresentaram os maiores teores médios da referida glicoproteína, entre todos os grupos experimentais. De acordo com JAIN (1993), a capacidade total de ligação do ferro é mensurada pela concentração de transferrina sérica, e a referida capacidade de ligação do ferro aumenta nos estados ferropênicos e diminui nas leucemias.

No que se diz respeito às IgG de cadeias leves (Tabela 4), os teores séricos de cães de controle foram significativamente maiores que aqueles dos cães anêmicos, exceção feita aos portadores de AHIM secundária, que não diferiram significativamente de nenhum grupo, sugerindo estímulo mais intenso à resposta imune por parte dos animais de controle. Com relação à haptoglobina (Tabela 3), verificou-se que sua concentração sérica foi menor nos cães de controle e que diferiu de forma significativa se comparada àquela obtida para os cães anêmicos. De acordo com JONES \& GRUFFYDD-JONES (1991), a concentração sérica de haptoglobina está elevada na maioria dos casos de AHIM em cães, possivelmente em consequência da fase aguda da resposta inflamatória patenteada por forte ativação de macrófagos. VAN DEN BROEK(1992) relata 
Tabela 1 - Médias, desvios-padrão (DP) e valores mínimos (VMi) e máximos (VMa) dos teores séricos das frações proteicas com peso variando entre 165.000Da e 118.000Da obtidas por fracionamento em gel de poliacrilamida contendo doudecil sulfato de sódio (SDS-PAGE) dos grupos 1 (controle), 2 (anemia regenerativa), 3 (anemia arregenerativa), 4 (AHIM $1^{\underline{a}}$ ) e 5 (AHIM 2 $2^{\underline{a}}$ ). Jaboticabal, 2008.

\begin{tabular}{|c|c|c|c|c|c|}
\hline $\begin{array}{l}\text { Proteína sérica } \\
\text { (Da) }\end{array}$ & Grupos & $\begin{array}{l}\text { Média } \pm D P \\
\left(m g d L^{-1}\right)\end{array}$ & $\begin{array}{c}\text { VMI } \\
\left(\mathrm{mg} \mathrm{dL}^{-1}\right)\end{array}$ & $\begin{array}{c}\text { VMA } \\
\left(\mathrm{mg} \mathrm{dL}^{-1}\right)\end{array}$ & Tukey* \\
\hline \multirow{5}{*}{ NI (PM 165.000) } & 1 & $39,44 \pm 28,99$ & 4,00 & 112,00 & $\mathrm{~b}$ \\
\hline & 2 & $42,56 \pm 29,87$ & 136,00 & 2,00 & $\mathrm{~b}$ \\
\hline & 3 & $41,72 \pm 29,49$ & 12,00 & 108,00 & $\mathrm{~b}$ \\
\hline & 4 & $97,69 \pm 21,21$ & 68,00 & 161,00 & $\mathrm{a}$ \\
\hline & 5 & $40,54 \pm 13,47$ & 26,00 & 77,00 & $\mathrm{~b}$ \\
\hline \multirow{5}{*}{ NI (PM 158.000) } & 1 & $56,84 \pm 36,39$ & 0,00 & 107,00 & $\mathrm{a}$ \\
\hline & 2 & $43,67 \pm 26,67$ & 5,00 & 84,00 & $\mathrm{a}$ \\
\hline & 3 & $37,62 \pm 25,71$ & 2,00 & 85,00 & $\mathrm{a}$ \\
\hline & 4 & $43,26 \pm 18,98$ & 18,00 & 83,00 & $\mathrm{a}$ \\
\hline & 5 & $42,45 \pm 17,78$ & 11,00 & 85,00 & $\mathrm{a}$ \\
\hline \multirow{5}{*}{ NI (PM 150.000) } & 1 & $11,04 \pm 10,65$ & 0,00 & 39,00 & $\mathrm{~b}$ \\
\hline & 2 & $29,93 \pm 18,70$ & 1,00 & 83,00 & $\mathrm{a}$ \\
\hline & 3 & $24,99 \pm 21,04$ & 1,00 & 76,00 & $\mathrm{a}$ \\
\hline & 4 & $22,54 \pm 7,43$ & 12,00 & 360,00 & $\mathrm{ab}$ \\
\hline & 5 & $31,16 \pm 11,19$ & 15,00 & 54,00 & $\mathrm{a}$ \\
\hline \multirow{5}{*}{ IgA (PM 142.000) } & 1 & $21,16 \pm 12,04$ & 2,00 & 59,00 & $\mathrm{~b}$ \\
\hline & 2 & $30,09 \pm 13,37$ & 6,00 & 52,00 & $\mathrm{ab}$ \\
\hline & 3 & $27,12 \pm 19,16$ & 4,00 & 79,00 & $\mathrm{ab}$ \\
\hline & 4 & $32,09 \pm 1,90$ & 19,00 & 48,00 & $\mathrm{a}$ \\
\hline & 5 & $29,13 \pm 7,41$ & 13,00 & 42,00 & $\mathrm{ab}$ \\
\hline \multirow{5}{*}{ NI (PM 122.000) } & 1 & $25.52 \pm 16,19$ & 0,00 & 72,00 & a \\
\hline & 2 & $15,11 \pm 14,98$ & 0,00 & 38,00 & $\mathrm{~b}$ \\
\hline & 3 & $18,91 \pm 16,07$ & 0,00 & 53,00 & $\mathrm{ab}$ \\
\hline & 4 & $1,62 \pm 1,51$ & 0,00 & 6,00 & $\mathrm{C}$ \\
\hline & 5 & $15,40 \pm 8,44$ & 0,00 & 31,00 & $\mathrm{~b}$ \\
\hline \multirow{5}{*}{ NI (PM 118.000) } & 1 & $15,56 \pm 10,73$ & 0,00 & 37,00 & $\mathrm{ab}$ \\
\hline & 2 & $24,88 \pm 17,97$ & 4,00 & 73,00 & $\mathrm{a}$ \\
\hline & 3 & $24,51 \pm 21,97$ & 0,00 & 89,00 & a \\
\hline & 4 & $12,88 \pm 5,89$ & 2,00 & 28,00 & $\mathrm{~b}$ \\
\hline & 5 & $19,32 \pm 11,34$ & 6,00 & 53,00 & $\mathrm{ab}$ \\
\hline
\end{tabular}

aumento da concentração sérica de haptoglobina em doenças hemolíticas e, segundo ANDERSSON et al. (1998) eANDERSSON \& SEVELIUS (2001), há aumento na concentração de haptoglobina na maioria dos casos de anemia hemolítica. De acordo com ECKERSALL et al. (1999), a concentração de haptoglobina para cães saudáveis situa-se entre 0 e $300 \mathrm{mg} \mathrm{dL}^{-1}$ e, para MARTINEZ-SUBIELAet al. (2004), de 30 a 180 $\mathrm{mg} \mathrm{dL}^{-1}$. No caso do protocolo experimental em questão, o grupo de controle apresentou concentração sérica de haptoglobina de $28,72 \pm 19,66 \mathrm{mg} \mathrm{dL}^{-1}$.
Com relação à ceruloplasmina (Tabela 2), notou-se decréscimo significativo de sua concentração nos cães anêmicos. De acordo com ECKERSALL et al. (1999) e MARTINEZ-SUBIELA et al. (2004), pode ocorrer aumento ou diminuição na concentração sérica de ceruloplasmina nos episódios de hemólise, de acordo com a concentração de hemoglobina.

É interessante observar que nesse protocolo experimental a proteína de peso molecular igual a 165.000Da (Tabela 1) foi encontrada significativamente em maior concentração nos cães com 
Tabela 2 - Médias, desvios-padrão (DP) e valores mínimos (VMi) e máximos (VMa) dos teores séricos das frações proteicas com peso variando entre 115.000Da e 78.000Da obtidas por fracionamento em gel de poliacrilamida contendo doudecil sulfato de sódio (SDS-PAGE) dos grupos 1 (controle), 2 (anemia regenerativa), 3 (anemia arregenerativa), 4 (AHIM $1^{\text {a }}$ ) e 5 (AHIM 2 ${ }^{\mathrm{a}}$ ). Jaboticabal, 2008.

\begin{tabular}{|c|c|c|c|c|c|}
\hline $\begin{array}{l}\text { Proteína sérica } \\
\text { (Da) }\end{array}$ & Grupos & $\begin{array}{l}\text { Média } \pm D P \\
\left(\mathrm{mg} \mathrm{dL}^{-1}\right)\end{array}$ & $\begin{array}{c}\text { VMI } \\
\left(\mathrm{mg} \mathrm{dL}^{-1}\right)\end{array}$ & $\begin{array}{c}\text { VMA } \\
\left(\mathrm{mg} \mathrm{dL}^{-1}\right)\end{array}$ & Tukey* \\
\hline \multirow{5}{*}{ NI (PM 115.000) } & 1 & $33,16 \pm 25,33$ & 0,00 & 75,00 & $\mathrm{ab}$ \\
\hline & 2 & $41,28 \pm 19,84$ & 10,00 & 102,00 & $\mathrm{a}$ \\
\hline & 3 & $36,47 \pm 24,89$ & 0,00 & 98,00 & $\mathrm{a}$ \\
\hline & 4 & $33,20 \pm 14,14$ & 13,00 & 69,00 & $\mathrm{ab}$ \\
\hline & 5 & $20,39 \pm 10,04$ & 0,00 & 40,00 & $\mathrm{~b}$ \\
\hline \multirow{5}{*}{ NI (PM 110.000) } & 1 & $1,04 \pm 4,21$ & 0,00 & 21,00 & $\mathrm{~b}$ \\
\hline & 2 & $26,47 \pm 20,62$ & 0,00 & 80,00 & $\mathrm{a}$ \\
\hline & 3 & $30,06 \pm 23,90$ & 0,00 & 88,00 & $\mathrm{a}$ \\
\hline & 4 & $28,14 \pm 8,12$ & 15,00 & 39,00 & $\mathrm{a}$ \\
\hline & 5 & $35,08 \pm 14,12$ & 11,00 & 65,00 & $\mathrm{a}$ \\
\hline \multirow{5}{*}{$\begin{array}{l}\text { Ceruloplasmina } \\
\text { (PM 105.000) }\end{array}$} & 1 & $45,16 \pm 30,10$ & 14,00 & 124,00 & $\mathrm{a}$ \\
\hline & 2 & $26,67 \pm 24,15$ & 2,00 & 119,00 & $\mathrm{~b}$ \\
\hline & 3 & $19,28 \pm 20,44$ & 1,50 & 95,00 & $\mathrm{~b}$ \\
\hline & 4 & $22,87 \pm 7,28$ & 13,00 & 37,00 & $\mathrm{~b}$ \\
\hline & 5 & $22,72 \pm 15,00$ & 4,00 & 58,00 & $\mathrm{~b}$ \\
\hline \multirow{5}{*}{$\begin{array}{l}\text { Fosforilase } \\
\text { (PM 95.000) }\end{array}$} & 1 & $4,60 \pm 3,54$ & 0,00 & 14,00 & $\mathrm{~b}$ \\
\hline & 2 & $59,57 \pm 39,95$ & 3,00 & 194,00 & $\mathrm{a}$ \\
\hline & 3 & $62,68 \pm 26,46$ & 8,00 & 106,00 & $\mathrm{a}$ \\
\hline & 4 & $67,28 \pm 29,92$ & 7,00 & 116,00 & $\mathrm{a}$ \\
\hline & 5 & $62,52 \pm 38,29$ & 2,00 & 143,00 & $\mathrm{a}$ \\
\hline \multirow{5}{*}{$\begin{array}{l}\text { Transferrina } \\
\text { (PM 82.000) }\end{array}$} & 1 & $51,60 \pm 26,72$ & 25,00 & 145,00 & C \\
\hline & 2 & $2.132,66 \pm 715,46$ & 202,00 & 3543,00 & $\mathrm{~b}$ \\
\hline & 3 & $1.883,76 \pm 347,50$ & 1156,00 & 2677,00 & $\mathrm{~b}$ \\
\hline & 4 & $2.739,78 \pm 559,49$ & 2021,00 & 3941,00 & $\mathrm{a}$ \\
\hline & 5 & $2.060,42 \pm 434,92$ & 1342,00 & 2898,00 & $\mathrm{~b}$ \\
\hline \multirow{5}{*}{$\begin{array}{l}\text { Hemopexina } \\
\text { (PM 78.000) }\end{array}$} & 1 & $127,60 \pm 50,28$ & 105,00 & 353,00 & $\mathrm{a}$ \\
\hline & 2 & $124,48 \pm 70,84$ & 14,00 & 331,00 & $a b$ \\
\hline & 3 & $98,32 \pm 75,99$ & 16,00 & 353,00 & $\mathrm{ab}$ \\
\hline & 4 & $82,84 \pm 15,57$ & 53,00 & 111,00 & $\mathrm{~b}$ \\
\hline & 5 & $96,40 \pm 34,96$ & 32,00 & 182,00 & $\mathrm{ab}$ \\
\hline
\end{tabular}

AHIM primária. No caso da proteína de peso molecular igual a 110.000Da (Tabela 2), elevadas concentrações séricas foram evidenciadas significativamente nos cães anêmicos. Além disso, verificou-se que as concentrações séricas das proteínas de pesos moleculares iguais a 56.000 e 58.000Da (Tabela 3) apresentaram-se significativamente maiores nos cães de controle, enquanto que a proteína de peso molecular igual a 25.000Da (Tabela 4) mostrou-se com concentrações significativamente baixas em cães com
AHIM primária. É muito provável que tais proteínas estejam envolvidas na fisiopatogenia da anemia, inclusive imunomediada.

Ao serem comparados os traçados eletroforéticos de animais com AHIMs primária e secundária (grupos 4 e 5 , respectivamente) com os cães dos outros grupos (1, 2 e 3), constatou-se que os animais com AHIM apresentaram uma fração proteica com peso molecular de 68.000Da (Tabela 3), não encontrada no proteinograma dos grupos 1 , 2 e 3 . É

Ciência Rural, v.40, n.4, abr, 2010. 
Tabela 3 - Médias, desvios-padrão (DP) e valores mínimos (VMi) e máximos (VMa) dos teores séricos das frações proteicas com peso variando entre 68.000Da e 45.000Da obtidas por fracionamento em gel de poliacrilamida contendo doudecil sulfato de sódio (SDS-PAGE) dos grupos 1 (controle), 2 (anemia regenerativa), 3 (anemia arregenerativa), 4 (AHIM $1^{\underline{a}}$ ) e 5 (AHIM 2 $2^{\underline{a}}$ ). Jaboticabal, 2008.

\begin{tabular}{|c|c|c|c|c|c|}
\hline $\begin{array}{l}\text { Proteína sérica } \\
\text { (Da) }\end{array}$ & Grupos & $\begin{array}{l}\text { Média } \pm D P \\
\left(\mathrm{mg} \mathrm{dL}^{-1}\right)\end{array}$ & $\begin{array}{c}\text { VMI } \\
\left(\mathrm{mg} \mathrm{dL}^{-1}\right)\end{array}$ & $\begin{array}{c}\text { VMA } \\
\left(\mathrm{mg} \mathrm{dL}^{-1}\right)\end{array}$ & Tukey* \\
\hline \multirow{5}{*}{ NI (PM 68.000) } & 1 & $0,00 \pm 0,00$ & 0,00 & 0,00 & $\mathrm{~b}$ \\
\hline & 2 & $0,00 \pm 0,00$ & 0,00 & 0,00 & $\mathrm{~b}$ \\
\hline & 3 & $0,00 \pm 0,00$ & 0,00 & 0,00 & $\mathrm{~b}$ \\
\hline & 4 & $203,32 \pm 187,21$ & 11,26 & 407,20 & $\mathrm{a}$ \\
\hline & 5 & $194,54 \pm 158,67$ & 0,00 & 356,00 & $\mathrm{a}$ \\
\hline \multirow{5}{*}{$\begin{array}{l}\text { Albumina } \\
\text { (PM 66.000) }\end{array}$} & 1 & $3.509,76 \pm 135,80$ & 2329,00 & 9408,00 & $\mathrm{a}$ \\
\hline & 2 & $1.962,44 \pm 861,38$ & 800,00 & 4997,00 & $\mathrm{~b}$ \\
\hline & 4 & $1.913,12 \pm 462,29$ & 1349,00 & 2913,00 & $\mathrm{~b}$ \\
\hline & 3 & $1968,92 \pm 450,33$ & 1212,00 & 3308,00 & $\mathrm{~b}$ \\
\hline & 5 & $2.066,24 \pm 567,81$ & 923,00 & 2958,00 & $\mathrm{~b}$ \\
\hline \multirow{5}{*}{$\begin{array}{l}\text { Alfa-anti-tripsina } \\
\text { (PM 62.000) }\end{array}$} & 1 & $28,32 \pm 12,66$ & 0,00 & 47,00 & c \\
\hline & 2 & $30,32 \pm 20,64$ & 12,00 & 95,00 & C \\
\hline & 3 & $64,12 \pm 47,27$ & 10,00 & 201,00 & $\mathrm{a}$ \\
\hline & 4 & $55,98 \pm 16,35$ & 25,00 & 81,00 & $\mathrm{ab}$ \\
\hline & 5 & $36,76 \pm 18,09$ & 10,00 & 84,00 & bc \\
\hline \multirow{5}{*}{ NI (PM 58.000) } & 1 & $183,72 \pm 128,74$ & 0,00 & 482,00 & $\mathrm{a}$ \\
\hline & 2 & $22,40 \pm 14,58$ & 5,00 & 65,00 & $\mathrm{~b}$ \\
\hline & 3 & $25,90 \pm 18,37$ & 7,90 & 82,00 & $\mathrm{~b}$ \\
\hline & 4 & $26,79 \pm 6,85$ & 16,00 & 38,00 & $\mathrm{~b}$ \\
\hline & 5 & $43,87 \pm 21,90$ & 12,00 & 93,00 & $\mathrm{~b}$ \\
\hline \multirow{5}{*}{ NI (PM 56.000) } & 1 & $266,84 \pm 318,21$ & 0,00 & 1550,00 & $\mathrm{a}$ \\
\hline & 2 & $24,59 \pm 13,47$ & 0,00 & 63,00 & $\mathrm{~b}$ \\
\hline & 3 & $16,22 \pm 9,50$ & 0,00 & 36,00 & $\mathrm{~b}$ \\
\hline & 4 & $18,65 \pm 5,06$ & 11,00 & 26,00 & $\mathrm{~b}$ \\
\hline & 5 & $12,72 \pm 6,54$ & 5,00 & 34,00 & $\mathrm{~b}$ \\
\hline \multirow{5}{*}{$\begin{array}{l}\text { Haptoglobina } \\
\text { (PM 45.000) }\end{array}$} & 1 & $28,72 \pm 19,66$ & 8,00 & 84,00 & $\mathrm{~b}$ \\
\hline & 2 & $87,80 \pm 48,84$ & 21,00 & 206,00 & $\mathrm{a}$ \\
\hline & 3 & $86,96 \pm 39,97$ & 27,00 & 195,00 & $\mathrm{a}$ \\
\hline & 4 & $88,97 \pm 32,70$ & 16,00 & 166,00 & $\mathrm{a}$ \\
\hline & 5 & $82,72 \pm 33,73$ & 25,00 & 15800 & $\mathrm{a}$ \\
\hline
\end{tabular}

bem provável que a identificação dessa proteína possa contribuir para um melhor entendimento da fisiopatogenia das AHIMs em cães.

\section{CONCLUSÕES}

Nas condições de realização do ensaio em questão e com base nos resultados obtidos, conclui-se que diferentes frações seroproteicas estão envolvidas na fenomenologia das anemias, inclusive aquelas de causa imune. A presença de uma fração

proteica de peso molecular igual a $68.000 \mathrm{Da}$ em cães portadores de AHIMs primária e secundária merece investigação ulterior, visando a uma efetiva contribuição para o diagnóstico clínico-patológico das anemias imunomediadas.

\section{APOIO FINANCEIRO}

Fundação de Amparo à Pesquisa do Estado de São Paulo - FAPESP (processo 04/10405-9).

Ciência Rural, v.40, n.4, abr, 2010. 
Tabela 4 - Médias, desvios-padrão (DP) e valores mínimos (VMi) e máximos (VMa) dos teores séricos das frações proteicas com peso variando entre $40.000 \mathrm{Da}$ e $18.000 \mathrm{Da}$ obtidas por fracionamento em gel de poliacrilamida contendo doudecil sulfato de sódio

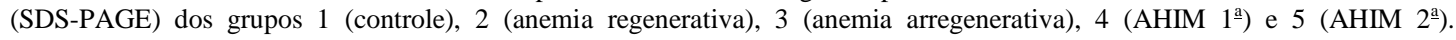
Jaboticabal, 2008.

\begin{tabular}{|c|c|c|c|c|c|}
\hline $\begin{array}{c}\text { Proteína sérica } \\
\text { (Da) }\end{array}$ & Grupos & $\begin{array}{c}\text { Média } \pm \mathrm{DP} \\
\left(\mathrm{mg} \mathrm{dL}^{-1}\right)\end{array}$ & $\begin{array}{c}\text { VMI } \\
\left(\mathrm{mg} \mathrm{dL}^{-1}\right)\end{array}$ & $\begin{array}{c}\text { VMA } \\
\left(\mathrm{mg} \mathrm{dL}^{-1}\right)\end{array}$ & Tukey* \\
\hline \multirow{5}{*}{$\begin{array}{l}\text { Glicoproteína ácida } \\
\text { (PM 40.000) }\end{array}$} & 1 & $14,60 \pm 6,58$ & 2,00 & 24,00 & c \\
\hline & 2 & $28,52 \pm 11,21$ & 0,00 & 63,00 & $\mathrm{~b}$ \\
\hline & 3 & $54,80 \pm 27,83$ & 12,00 & 95,00 & a \\
\hline & 4 & $11,61 \pm 2,91$ & 7,00 & 16,00 & c \\
\hline & 5 & $7,23 \pm 3,91$ & 0,00 & 15,00 & c \\
\hline \multirow{5}{*}{ NI (PM 35.000) } & 1 & $442,16 \pm 264,63$ & 104,00 & 1104,00 & $\mathrm{ab}$ \\
\hline & 2 & $578,54 \pm 393,20$ & 127,00 & 1609,00 & a \\
\hline & 3 & $388,48 \pm 142,83$ & 150,00 & 644,00 & $\mathrm{~b}$ \\
\hline & 4 & $359,76 \pm 106,76$ & 163,00 & 568,00 & b \\
\hline & 5 & $583,60 \pm 149,70$ & 238,00 & 956,00 & a \\
\hline \multirow{5}{*}{$\begin{array}{l}\text { IgG Cadeia Leve } \\
\text { (PM 31.000) }\end{array}$} & 1 & $878,64 \pm 45,52$ & 350,00 & 2646,00 & a \\
\hline & 2 & $539,94 \pm 355,83$ & 114,00 & 1674,00 & $\mathrm{~b}$ \\
\hline & 3 & $542,84 \pm 160,94$ & 323,00 & 886,00 & $\mathrm{~b}$ \\
\hline & 4 & $486,68 \pm 123,29$ & 250,00 & 795,00 & b \\
\hline & 5 & $676,40 \pm 249,93$ & 419,00 & 1158,00 & $\mathrm{ab}$ \\
\hline \multirow{5}{*}{ NI (PM 25.000) } & 1 & $34,76 \pm 22,53$ & 10,00 & 85,00 & a \\
\hline & 2 & $45,86 \pm 28,44$ & 1,00 & 98,00 & a \\
\hline & 3 & $41,75 \pm 38,47$ & 0,00 & 161,00 & a \\
\hline & 4 & $12,74 \pm 8,76$ & 0,00 & 27,00 & $\mathrm{~b}$ \\
\hline & 5 & $34,08+15,49$ & 12,00 & 77,00 & a \\
\hline \multirow{5}{*}{ NI (PM 18.000) } & 1 & $27,64 \pm 21,32$ & 0,00 & 63,00 & a \\
\hline & 2 & $12,38 \pm 12,18$ & 1,00 & 51,00 & bc \\
\hline & 3 & $7,19 \pm 7,86$ & 0,00 & 26,00 & c \\
\hline & 4 & $3,74 \pm 4,47$ & 0,00 & 18,00 & c \\
\hline & 5 & $20,64 \pm 10,61$ & 0,00 & 41,00 & $\mathrm{ab}$ \\
\hline
\end{tabular}

*teste de Tukey - médias com a mesma letra não diferem significativamente entre si pelo teste de Tukey - P>0,05

$\mathrm{NI}$ - não identificada

PM - peso molecular.

\section{REFERÊNCIAS}

ANDERSSON, M. et al. Disease-related variations of the glycosylation of haptoglobin in the dog. Journal of Comparative Pathology, v.119, n.3, p.227-238, 1998.

ANDERSSON, M.; SEVELIUS, E. Abnormal microheterogeneity of haptoglobin in serum from dogs nith various diseases. Veterinary Record, v.148, n.1, p.14-17, 2001.

BRANDÃO, L.P. et al. Anemia hemolítica imunomediada em cão- diagnóstico e tratamento. Clínica Veterinária, n.44, p.46-54, 2003.

CERÓN, J.J. et al. Acute phase proteins in dogs and cats: current knowledge and future perspectives. Veterinary
Clinical Pathology, v.34, n.2, p.85-99, 2005. Disponível em: <http://www3.interscience.wiley.com/journal/120177474/ abstract?CRETRY=1\&SRETRY=0>. Acesso em: 21 fev. 2010. doi: 10.1111/j.1939-165X.2005.tb00019.x.

ECKERSALL, P.D. et al. An automated biochemical assay for haptoglobin: prevention of interference from albumin. Comparative Haematology International, v.9, n.5, p.117124, 1999. Disponível em: <http://www.springerlink.com/ content/k76340501ur3t342>. Acesso em: 21 fev. 2010. doi: 10.1007/BF02600369.

ECKERSALL, P.D Recent advances and future prospects for the use of acute phase proteins as markers of disease in animals. Revue de Médecine Vétérinaire, v.151, p.577-584, 2000. 
FAGLIARI, J.J.; SILVA, S.L. Hemograma e proteinograma plasmático de eqüinos hígidos e de eqüinos acometidos por abdômen agudo, antes e após laparotomia. Arquivo Brasileiro de Medicina Veterinária e Zootecnia, v.54, n.6, p.559-567, 2002. Disponível em: <http://www.scielo.br/scielo.php?pid=S0102$09352002000600001 \&$ script $=$ sci_abstract\&tlng=pt $>$. Acesso em: 21 fev. 2010. doi: 10.1590/S0102-09352002000600001.

FELDMAN, B.F. et al. Veterinary hematology. 5.ed. Philadelphia: Lippincott Williams \& Wilkins, 2000. 1344p.

GODOY, A.V. et al. Perfil eletroforético de proteínas séricas do sangue do cordão umbilical de cães. Ciência Rural, v.32, n.2, p.531-535, 2006. Disponível em: <http://www.scielo.br/ scielo.php ? script =sci_abstract \& pid=S 0103 $84782006000200026 \& \operatorname{lng}=\mathrm{en} \& \mathrm{nrm}=\mathrm{i} \& \mathrm{t} \operatorname{lng}=\mathrm{pt}>$. Acesso em: 21 fev. 2010. doi: 10.1590/S0103-84782006000200026.

GORDON, J.N. Electrophoresis of proteins in polyacrylamide and starch gels. New York: Elsevier, 1995. 213p.

JAIN, N.C. Essentials of veterinary hematology. Philadelphia: Lea \& Febiger, 1993. 417p.

JONES, D.R.E.; GRUFFYDD-JONES, T.J. The haematological consequences of immune-mediated anaemia in the dog. Comparative Haematololy International, v.1, n.2, p 8390, 1991. Disponível em: <http://www.springerlink.com/ content/p4n362k71q357017>. Acesso em: 21 fev. 2010. doi: 10 10.1007/BF00422878.
KANEKO, J.J. et al. Clinical biochemistry of domestic animals. 5.ed. New York: Academic, 1997. 932p.

LAEMMLI, U.K. Cleavage of structural proteins during the assembly of the head of baceriophage $\mathrm{T}_{4}$. Nature, v.227, p.680-685, 1970. Disponível em: <http://www.nature.com/ nature/journal/v227/n5259/abs/227680a0.html>. Acesso em: 21 fev. 2010. doi: 10.1038/227680a0.

MARTINEZ-SUBIELA, S. et al. Effects of differents glucocorticoid treatments on serum acute phase proteins in dogs. Veterinary Record, v.154, p.814-817, 2004

MURATA, H. et al. Current research on acute phase proteins in veterinary diagnosis: an overview. Veterinary Journal, v.168, n.1, p.28-40, 2004.

STEINMAN, L. Escape from "horror autotoxicus": Pathogenesis and treatment of autoimmune disease. Cell, v.80, p.7-10, 1995.

STROTTMANN, D.M. et al. Diagnóstico e estudo sorológico da infecção pelo parvovírus canino em cães de Passo Fundo, Rio Grande do Sul, Brasil. Ciência Rural, v.38, n.2, p.531535, 2008. Disponível em: <http://www.scielo.br/ scielo.php? script = sci_art text \& pid = S 0103 84782008000200017>. Acesso em: 21 fev. 2010. doi: $10.1590 /$ S0103-84782008000200017.

VAN DEN BROEK, A.H.M. Serum protein values in canine diabetes mellitus, hypothyroidism and hypoadrenocorticism. British Veterinary Journal. v.148, n.3, p.259-262, 1992. 